\title{
Thickness-dependent properties of ultrathin bismuth and antimony chalcogenide films formed by physical vapor deposition and their application in thermoelectric generators
}

\author{
J. Andzane a , A. Felsharuk ${ }^{\text {a, c }}$, A. Sarakovskis ${ }^{\text {d }}$, U. Malinovskis a , E. Kauranens ${ }^{\text {a }}$, \\ M. Bechelany ${ }^{\mathrm{e}}$, K.A. Niherysh ${ }^{\mathrm{a}, \mathrm{c}}$, I.V. Komissarov ${ }^{\mathrm{c}}$, D. Erts ${ }^{\mathrm{a}}$, b, * \\ a Institute of Chemical Physics, Riga, LV-1586, Latvia \\ ${ }^{\mathrm{b}}$ Faculty of Chemistry, University of Latvia, Riga, LV-1586, Latvia \\ ${ }^{c}$ Belarusian State University of Informatics and Radioelectronics, Minsk, Republic of Belarus \\ ${ }^{\mathrm{d}}$ Institute of Solid State Physics, University of Latvia, Riga, LV-1063, Latvia \\ e Institut Européen des Membranes, IEM - UMR 5635, ENSCM, CNRS, University of Montpellier, Montpellier, France
}

\section{A R T I C L E I N F O}

Article history:

Received 9 June 2020

Received in revised form

6 November 2020

Accepted 15 November 2020

Available online 27 November 2020

\section{Keywords:}

Ultrathin film

Narrow band gap layered semiconductor

Bismuth chalcogenide

Antimony telluride

Thickness-dependent thermoelectric

properties

\begin{abstract}
A B S T R A C T
In this work, a simple cost-effective physical vapor deposition method for obtaining high-quality $\mathrm{Bi}_{2} \mathrm{Se}_{3}$ and $\mathrm{Sb}_{2} \mathrm{Te}_{3}$ ultrathin films with thicknesses down to $5 \mathrm{~nm}$ on mica, fused quartz, and monolayer graphene substrates is reported. Physical vapor deposition of continuous $\mathrm{Sb}_{2} \mathrm{Te}_{3}$ ultrathin films with thicknesses $10 \mathrm{~nm}$ and below is demonstrated for the first time. Studies of thermoelectrical properties of synthesized $\mathrm{Bi}_{2} \mathrm{Se}_{3}$ ultrathin films deposited on mica indicated opening of a hybridization gap in $\mathrm{Bi}_{2} \mathrm{Se}_{3}$ ultrathin films with thicknesses below $6 \mathrm{~nm}$. Both $\mathrm{Bi}_{2} \mathrm{Se}_{3}$ and $\mathrm{Sb}_{2} \mathrm{Te}_{3}$ ultrathin films showed the Seebeck coefficient and thermoelectrical power factors comparable with the parameters obtained for the highquality thin films grown by the molecular beam epitaxy method. Performance of the best $\mathrm{Bi}_{2} \mathrm{Se}_{3}$ and $\mathrm{Sb}_{2} \mathrm{Te}_{3}$ ultrathin films is tested in the two-leg prototype of a thermoelectric generator.
\end{abstract}

(C) 2020 Elsevier Ltd. All rights reserved.

\section{Introduction and background}

Thermoelectric materials and based technologies, enabling the direct conversion of heat to electricity, are expected to play an important role in solving one of the biggest global challenges, which is increase of energy efficiency of domestic and industrial processes by waste heat capturing and conversion to useful energy. A simplest thermoelectric generator (TEG) for heat-to-electricity conversion consists of two semiconductors with different ( $\mathrm{n}$ - and p-) types of electrical conductivity, joined at their ends. The performance of thermoelectric materials and devices is characterized by a dimensionless figure of merit ZT, defined as $S^{2} \sigma \mathrm{T} / \mathrm{k}$, where $\mathrm{S}$ is the Seebeck coefficient of the material, $\sigma$ is its electrical conductivity, $\mathrm{T}$ is absolute temperature, and $\mathrm{k}$ is thermal conductivity of the material. $S^{2} \sigma$ is usually referred as the power factor (PF) of

\footnotetext{
* Corresponding author.

E-mail address: donats.erts@lu.lv (D. Erts).
}

thermoelectric material. The common approaches in enhancement of ZT is maximizing of PF and/or reduction of thermal conductivity of the material [1]. However, interdependency of electrical and thermal conductivities hampers breakthrough enhancement of ZT of materials.

Bismuth and antimony chalcogenides $\left(\mathrm{Bi}_{2} \mathrm{Se}_{3}, \mathrm{Bi}_{2} \mathrm{Te}_{3}, \mathrm{Sb}_{2} \mathrm{Te}_{3}\right)$, layered narrow-band-gap semiconductors with recently discovered 3D topological insulator (TI) properties [2-4], are widely known as the best near-room temperature thermoelectric materials with n-type $\left(\mathrm{Bi}_{2} \mathrm{Se}_{3}, \mathrm{Bi}_{2} \mathrm{Te}_{3}\right)$ and p-type conductivity, useful for domestic waste heat conversion applications. These materials consist of charge neutralized layers (QLs) bonded together by van der Waals interaction. Each QL is formed by five covalently bonded atomic sheets (for example, $\mathrm{Se}-\mathrm{Bi}-\mathrm{Se}-\mathrm{Bi}-\mathrm{Se}$ ) and is $\sim 1 \mathrm{~nm}$ thick.

Recently, it was predicted that quantum confinement introduced by downsizing of the thermoelectric materials may result in enhancement of ZT of thermoelectric materials [5,6]. For example, it has been shown theoretically that the multiple sub-band structure, small band gap, and vicinity of materials with TI properties to 
a metallic state associated with an electronic topological transition are responsible for their superior TE performance [7]. Theoretical calculations performed for TI bismuth chalcogenide films [8,9] proved that the reduction of the thickness of thin film below $10 \mathrm{~nm}$ will result in noticeable quantum tunneling between the top and bottom surfaces and inducing of hybridization band gap near the Dirac point, resulting in improvement of existing ZT of the material by nearly an order of magnitude due to the disengagement of electrical and thermal conductivities of this material. At the same time, the other research groups predicted that the parallel contributing of coexisting in such TI systems surface and bulk states to the thermoelectric properties of the TI material may tend to cancel each other out, and ZT cannot be enhanced dramatically; however, some improvement of thermoelectrical properties of material could still be observed at optimal positions of Fermi levels [10]. Experimental investigation of properties of nanostructured materials of the bismuth and antimony chalcogenide family also showed different results. For example, properties of nanostructured n-type BiTe showed coexistence of distinct topological quantum phases in this material resulting on potential decoupling of thermal and electronic transport properties, which is the fundamentals for efficient thermoelectrics [11].

On the other hand, while the theoretically proposed thicknesses for the hybridization gap opening, leading to the disengagement of electrical and thermal conductivities and consequent improvement of ZT of the material are below $6 \mathrm{~nm}$ and $3 \mathrm{~nm}$ for $\mathrm{Bi}_{2} \mathrm{Se}_{3}$ and $\mathrm{Bi}_{2} \mathrm{Te}_{3}$, respectively [10], the experimental investigation of grown by molecular beam epitaxy (MBE) $\sim 5 \mathrm{~nm}$ thin $\left(\mathrm{Bi}_{1-\mathrm{x}} \mathrm{Sb}_{\mathrm{x}}\right)_{2} \mathrm{Te}_{3}$ and 5-30 nm thin $\mathrm{Bi}_{2} \mathrm{Se}_{3}$ films did not show any significant improvement from the bulk values of ZT $[12,13]$. Regarding $\mathrm{Sb}_{2} \mathrm{Te}_{3}$ thin films, while theoretical studies predicted significant sensitivity of Seebeck coefficient and electrical conductivity of these thin films to the thickness reduction down to $2 \mathrm{~nm}$, the experimental measurements were performed only for the $\mathrm{Sb}_{2} \mathrm{Te}_{3}$ thin films with thicknesses down to $30 \mathrm{~nm}$ fabricated by atomic layer deposition and revealed increase of the electrical conductivity but at the same time decrease of the Seebeck coefficient, resulting to reduction of thermoelectric efficiency of the material related to the contribution of surface states [14]. The method for gaining a thermoelectrical benefit from the $\mathrm{Sb}_{2} \mathrm{Te}_{3}$ thin film proposed by the aforementioned research was gapping the surface states and tuning the charge carrier concentration. However, the theoretically proposed thickness for hybridization gap opening in $\mathrm{Sb}_{2} \mathrm{Te}_{3}$ is $4 \mathrm{~nm}$ [10], and, to the best of our knowledge, the experimental research of the thermoelectric properties of $\mathrm{Sb}_{2} \mathrm{Te}_{3}$ thin films with thicknesses below $30 \mathrm{~nm}$ has not been yet performed.

This work is focused on development of a simple and costeffective physical vapor deposition (PVD) method of synthesis of $\mathrm{Bi}_{2} \mathrm{Se}_{3}$ and $\mathrm{Sb}_{2} \mathrm{Te}_{3}$ ultrathin films of thicknesses down to $5 \mathrm{~nm}$ on different (natural mica, quartz, graphene) substrates. Mica is recognized as an excellent non-electrically conductive substrate for the growth of layered materials as bismuth and antimony chalcogenides. Mica is a chemically inert substrate with atomically flat surface ideal for ultrathin films growth by van der Waals epitaxy. For example, the minimal reported thicknesses of the separate $\mathrm{Bi}_{2} \mathrm{Se}_{3}$ nanoplates PVD-deposited on synthetic fluorophlogopite mica were as small as $2-3 \mathrm{~nm}$ [15]. In this work, natural muscovite mica is used, which is much cheaper alternative to the synthetic mica. However, the drawbacks of mica substrates for thermoelectric measurements are its relatively high thermal conductivity, masking the real thermal conductivity of ultrathin films deposited on its surface. A good alternative to mica substrates for the thermoelectric measurements is fused quartz substrates, having low thermal conductivity. However, deposition of the ultrathin films on quartz substrates is challenging because of the presence of variety of chemical and mechanical defects on its surface. Finally, graphene is a very attractive substrate for the epitaxial growth of ultrathin $\mathrm{Bi}_{2} \mathrm{Se}_{3}$ and $\mathrm{Sb}_{2} \mathrm{Te}_{3}$ films because of the small lattice mismatch with these materials (2.9\% [16] and 4\% [17] for $\mathrm{Bi}_{2} \mathrm{Se}_{3}$ and $\mathrm{Sb}_{2} \mathrm{Te}_{3}$, respectively). Moreover, because of high electrical conductance graphene has a potential to be used simultaneously as the substrate for ultrathin films deposition and as the electrode for the measurements. Electrical and thermoelectric properties of $\mathrm{Bi}_{2} \mathrm{Se}_{3}$ and $\mathrm{Sb}_{2} \mathrm{Te}_{3}$ ultrathin films of thicknesses ranging from 5 to $15 \mathrm{~nm}$ are investigated, discussed, and compared with the properties of thin films grown by the MBE method. Performance of $\mathrm{Bi}_{2} \mathrm{Se}_{3}$ and $\mathrm{Sb}_{2} \mathrm{Te}_{3}$ ultrathin films with the best thermoelectric performance is tested in a prototype of the two-leg TEG.

\section{Results and discussion}

\subsection{Synthesis}

Previously, our group developed the PVD method for the Volmer-Weber growth of $\mathrm{Bi}_{2} \mathrm{Se}_{3}$ thin films on mica, glass, and graphene surfaces, using $\mathrm{Bi}_{2} \mathrm{Se}_{3}$ compound as a source material [18-20]. However, the minimal thicknesses of thin films grown by this method exceeded $50 \mathrm{~nm}$. In this work, to achieve deposition of thinner thin films, the $\mathrm{Bi}_{2} \mathrm{Se}_{3}$ source material was replaced with separate Bi and Se sources. The use of separate sources allowed to differentiate their evaporation rates by placing them in different temperature zones as shown in Fig. 1a.

The substrate was placed in the temperature region ensuring formation of stoichiometric $\mathrm{Bi}_{2} \mathrm{Se}_{3}[18,20]$. Presumably, the layerby-layer growth of $\mathrm{Bi}_{2} \mathrm{Se}_{3}$ ultrathin films when separate $\mathrm{Bi}$ and $\mathrm{Se}$ sources are used instead of $\mathrm{Bi}_{2} \mathrm{Se}_{3}$ powder can be explained by specifics of evaporation and deposition processes of different source materials. The evaporation of $\mathrm{Bi}_{2} \mathrm{Se}_{3}$ at temperatures above $427{ }^{\circ} \mathrm{C}$ has dissociative nature: $\mathrm{Bi}_{2} \mathrm{Se}_{3} \leftrightarrow 2 \mathrm{BiSe}$ (gas) $+1 / 2 \mathrm{Se}_{2}$ (gas) [21]. Because of the higher heat of formation of BiSe $\left(\sim 167 \mathrm{~kJ} \mathrm{~mol}^{-1}\right)$ than $\mathrm{Bi}_{2} \mathrm{Se}_{3}\left(\sim 140 \mathrm{~kJ} \mathrm{~mol}^{-1}\right)$ [22], the adsorbed on the substrate BiSe molecules diffuse across the surface until they reach the energetically favorable position. This process results in nucleation and further growth of $\mathrm{Bi}_{2} \mathrm{Se}_{3}$ islands [18]. In case of the use of separate $\mathrm{Bi}$ and Se sources, heat of vaporization of Se is nearly five times smaller than of $\mathrm{Bi}$ (37.7 and $179 \mathrm{~kJ} \mathrm{~mol}^{-1}$, respectively) [22]. The deposition process starts with evaporation and impinging of Se atoms on the whole substrate surface followed by evaporation of $\mathrm{Bi}$ and formation of the $\mathrm{Bi}_{2} \mathrm{Se}_{3}$ compound over all the surface of the substrate. Using this method, $\mathrm{Bi}_{2} \mathrm{Se}_{3}$ ultrathin films with thicknesses 5,6 , and $15 \mathrm{~nm}$ on mica substrates were prepared.

For the deposition of $\mathrm{Sb}_{2} \mathrm{Te}_{3}$ ultrathin films, the source material was placed in the center of the furnace hot zone (Fig. 1b). The mechanism of the $\mathrm{Sb}_{2} \mathrm{Te}_{3}$ growth differs from that of $\mathrm{Bi}_{2} \mathrm{Se}_{3}$, where $\mathrm{Bi}$ is mainly in the atomistic form. The dissociative evaporation of the $\mathrm{Sb}_{2} \mathrm{Te}_{3}$ compound can be described by the equation $\mathrm{Sb}_{2} \mathrm{Te}_{3} \leftrightarrow 1$ / $2 \mathrm{Sb}_{4}$ (gas) $+3 / 4 \mathrm{Te}_{2}$ (gas) [21]. Because of the high stability of $\mathrm{Sb}_{4}$ tetramers and their lower sticking coefficient to the substrate than $\mathrm{Sb}_{2} \mathrm{Te}_{3}$ [21,23], the $\mathrm{Sb}_{2} \mathrm{Te}_{3}$ deposition process occurs in three steps. Initially, the optimal for $\mathrm{Sb}_{2} \mathrm{Te}_{3}$ nucleation substrate temperature must be lower than the threshold for $\mathrm{Sb}_{2} \mathrm{Te}_{3}$ nucleation $\left(\sim 190{ }^{\circ} \mathrm{C}\right)$, but high enough to avoid Sb clustering. In the developed synthesis method, this condition is fulfilled when the temperature in the center of the quartz tube reaches $405-410^{\circ} \mathrm{C}$ and the nucleation of $\mathrm{Sb}_{2} \mathrm{Te}_{3}$ on the substrate takes place and may be visually observed. However, after the nucleation stage the substrate temperature can be increased by $10-20^{\circ} \mathrm{C}$ to improve the $\mathrm{Sb}_{2} \mathrm{Te}_{3}$ film quality $[21,23]$. At this step, the further increase of the temperature in the furnace tube center up to 415 or $420{ }^{\circ} \mathrm{C}$ and consequent increase of the substrate temperature resulted in formation of $5 \mathrm{~nm}$ and $7 \mathrm{~nm}$ thin 
a)
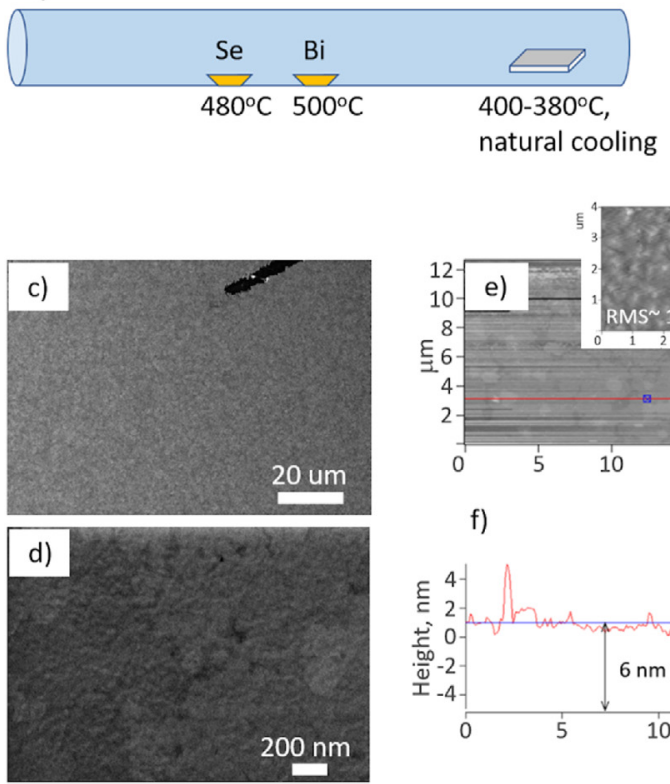

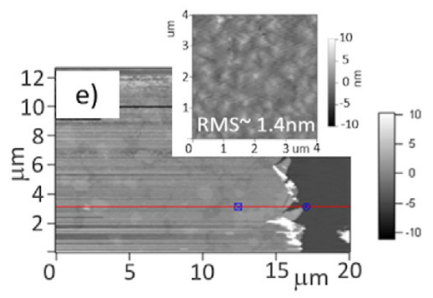

f)

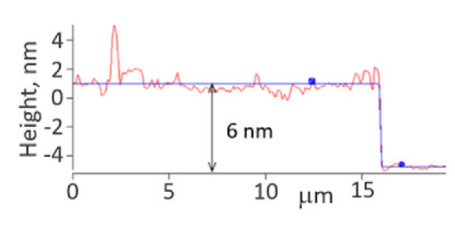

b)

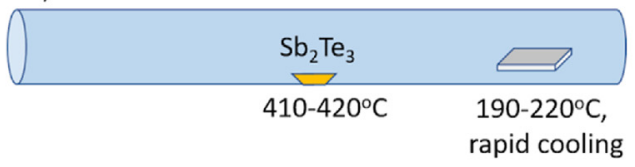

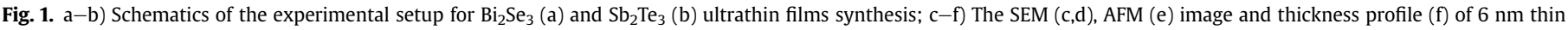

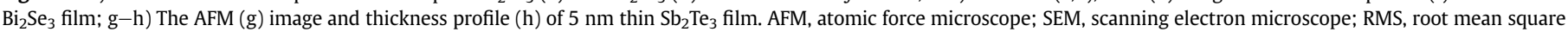
roughness.

$\mathrm{Sb}_{2} \mathrm{Te}_{3}$ films, respectively. This step is followed by immediate rapid cooling of the substrate in the inert atmosphere to preserve the $\mathrm{Sb}_{2} \mathrm{Te}_{3}$ ultrathin film of desired thickness.

The described methods of deposition of $\mathrm{Bi}_{2} \mathrm{Se}_{3}$ and $\mathrm{Sb}_{2} \mathrm{Te}_{3}$ films are effective for obtaining of ultrathin films with thicknesses down to $5 \mathrm{~nm}$ on the mica surface (Fig. $1 \mathrm{e}-\mathrm{h}$ ) and down to $8-10 \mathrm{~nm}$ on fused quartz and graphene substrates (Fig. S1).

\subsection{Structural characterization}

Low- and high-magnification scanning electron microscope (SEM) images (Fig. 1c,d; an artificial scratch in Fig. 1c is introduced for the thickness measurements) show that the obtained ultrathin films are uniform and fully fused. Surface scans (Fig. 1 e,g) and thickness profiles (Fig. $1 \mathrm{f}, \mathrm{h}$ ) performed by the atomic force microscope (AFM) for $6 \mathrm{~nm}$ thin $\mathrm{Bi}_{2} \mathrm{Se}_{3}$ film and $5 \mathrm{~nm}$ thin $\mathrm{Sb}_{2} \mathrm{Te}_{3}$ film show that these ultrathin films have smooth surface with the root mean square roughness (RMS) $\sim 1.4 \mathrm{~nm}$ and $\sim 1.7 \mathrm{~nm}$, respectively (insets in Fig. 1 e,g). Energy-dispersive X-ray spectroscopy (EDX) measurements of the ultrathin $\mathrm{Bi}_{2} \mathrm{Se}_{3}$ and $\mathrm{Sb}_{2} \mathrm{Te}_{3}$ films deposited on quartz substrates confirmed within the standard deviations the stoichiometric composition ( 40 [Bi, Sb]: 60 [Bi, Te] at \%) of these films. These results were supported by the X-ray photoelectron spectroscopy (XPS) analysis and Raman spectroscopy of ultrathin $\mathrm{Bi}_{2} \mathrm{Se}_{3}$ and $\mathrm{Sb}_{2} \mathrm{Te}_{3}$ films.

An example of XPS spectra of the $6 \mathrm{~nm}$ thin $\mathrm{Bi}_{2} \mathrm{Se}_{3}$ film is shown in Fig. 2 a,b. The XPS analysis showed the presence of Bi and Se in the material. In high-resolution spectra, the peaks corresponding to $\mathrm{Bi}_{4} \mathrm{f}_{7 / 2}$ and $\mathrm{Bi} 4 \mathrm{f}_{5 / 2}$ are located at $158.5 \mathrm{eV}$ and $163.8 \mathrm{eV}$, while the positions of Se $3 d_{5 / 2}$ and $S e 3 d_{3 / 2}$ peaks are located at $53.8 \mathrm{eV}$ and $54.6 \mathrm{eV}$, respectively.

The analysis of the presented in Fig. 2 c,d representative XPS spectra of the $5 \mathrm{~nm}$ thin $\mathrm{Sb}_{2} \mathrm{Te}_{3}$ film showed the presence of $\mathrm{Sb}$ and $\mathrm{Te}$ in the material. The detailed study of the spectra revealed the positions of $\mathrm{Sb}_{3 / 2}$ and $\mathrm{Sn} 3 \mathrm{~d}_{3 / 2}$ peaks located at $529.1 \mathrm{eV}$ and $538.5 \mathrm{eV}$, respectively, identified as metallic $\mathrm{Sb}$. The analysis of the
Te signal revealed the presence of metallic $T e 3 d_{5 / 2}$ and $T e 3 d_{3 / 2}$ peaks located at 573.2 and $583.6 \mathrm{eV}$, respectively.

For the both $\mathrm{Bi}_{2} \mathrm{Se}_{3}$ and $\mathrm{Sb}_{2} \mathrm{Te}_{3}$ ultrathin films, the detailed analysis of the XPS spectra revealed the presence of peaks related to the oxidized material. Shoulders in Bi4f spectra located at $159.3 \mathrm{eV}$ and $164.6 \mathrm{eV}$ (Fig. 2 a) corresponded to the oxidized surface of the $\mathrm{Bi}_{2} \mathrm{Se}_{3}$ film. A similar small intensity feature corresponding to oxidized Se is present in the spectrum of Se3d in the region of $59 \mathrm{eV}$ (Fig. 2 b). For $\mathrm{Sb}_{2} \mathrm{Te}_{3}$, the oxidized Sb peaks located at $530.8 \mathrm{eV}\left(3 \mathrm{~d}_{5 /}\right.$ 2) and $540.2 \mathrm{eV}\left(3 \mathrm{~d}_{3 / 2}\right)$ with the additional peak located at $531.5 \mathrm{eV}$ corresponding to $01 \mathrm{~s}$ signal (Fig. $2 \mathrm{c}$ ), as well as oxidized $\mathrm{Te} 3 \mathrm{~d}_{5 / 2}$ and $\mathrm{Te} \mathrm{d}_{3 / 2}$ peaks located at 576.8 and $587.2 \mathrm{eV}$ and Te monoxide located at $575.0 \mathrm{eV}$ and $585.5 \mathrm{eV}$ (Fig. $2 \mathrm{~d}$ ) were identified. The presence of oxidation-related peaks in the XPS spectra of ultrathin $\mathrm{Bi}_{2} \mathrm{Se}_{3}$ and $\mathrm{Sb}_{2} \mathrm{Te}_{3}$ films is related to the susceptibility of these materials to rapid oxidation in air [24,25], as the synthesized ultrathin films were stored under ambient conditions for several months.

Chemical composition of the samples based on the measured XPS deconvoluted peak intensities has been evaluated to confirm the stoichiometry of the material (Table 1 ).

Raman spectroscopy of the deposited on different substrates ultrathin $\mathrm{Bi}_{2} \mathrm{Se}_{3}$ and $\mathrm{Sb}_{2} \mathrm{Te}_{3}$ films identified typical characteristic $\mathrm{E}^{2} \mathrm{~g}$ and $\mathrm{A}^{2}{ }_{1 \mathrm{~g}}$ vibration modes appearing at the peak positions of $\sim 130 \mathrm{~cm}^{-1}$ and $\sim 173 \mathrm{~cm}^{-1}$ corresponding to $\mathrm{Bi}_{2} \mathrm{Se}_{3}$ (Fig. $3 \mathrm{a}$ ), and $\sim 117 \mathrm{~cm}^{-1}$ and $\sim 165 \mathrm{~cm}^{-1}$ corresponding to $\mathrm{Sb}_{2} \mathrm{Te}_{3}$ (Fig. $3 \mathrm{~b}$ ), which is consistent with the previous reports [26,27]. No significant deviations in the positions of the peak maxima were observed.

The X-ray diffraction (XRD) characterization of the ultrathin $\mathrm{Bi}_{2} \mathrm{Se}_{3}$ and $\mathrm{Sb}_{2} \mathrm{Te}_{3}$ films deposited on mica revealed that because of the very small thickness of the deposited $\mathrm{Bi}_{2} \mathrm{Se}_{3}$ films, the XRD diffraction peaks related to both $\mathrm{Bi}_{2} \mathrm{Se}_{3}$ and mica are overlapping, which greatly complicates spectra analysis (Fig. S2), while the XRD spectra of the ultrathin films deposited on quartz and graphene substrates allow to distinguish diffraction peaks related to the reflection planes of $\mathrm{Bi}_{2} \mathrm{Se}_{3}$ and $\mathrm{Sb}_{2} \mathrm{Te}_{3}$. Fig. 4 shows the representative XRD spectra of $6 \mathrm{~nm}$ thin $\mathrm{Bi}_{2} \mathrm{Se}_{3}$ film and $10 \mathrm{~nm}$ thin $\mathrm{Sb}_{2} \mathrm{Te}_{3}$ 

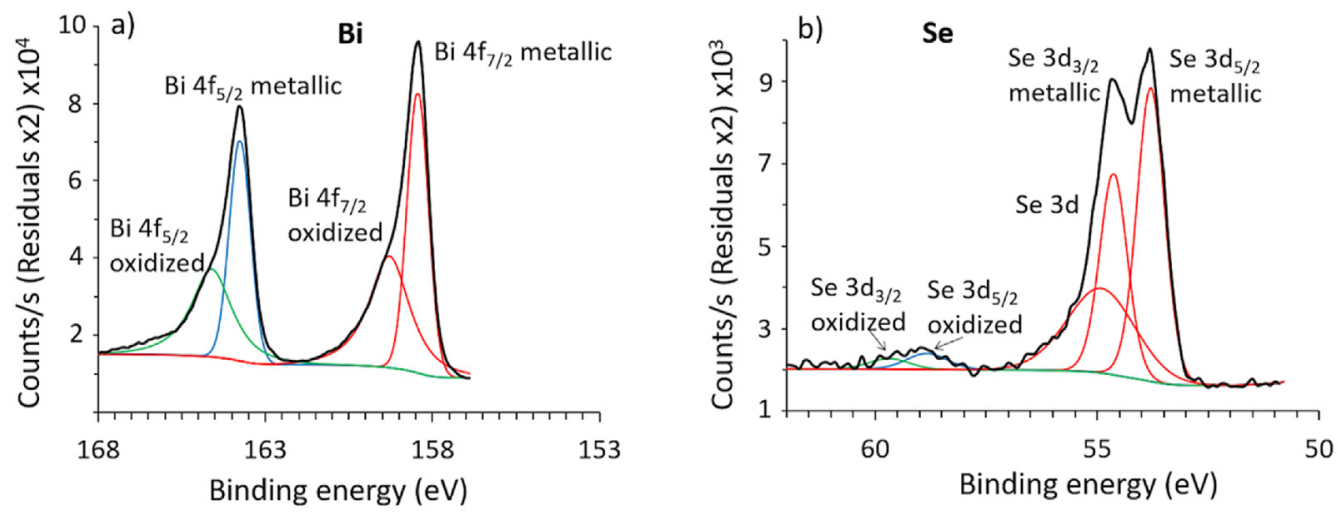

c)

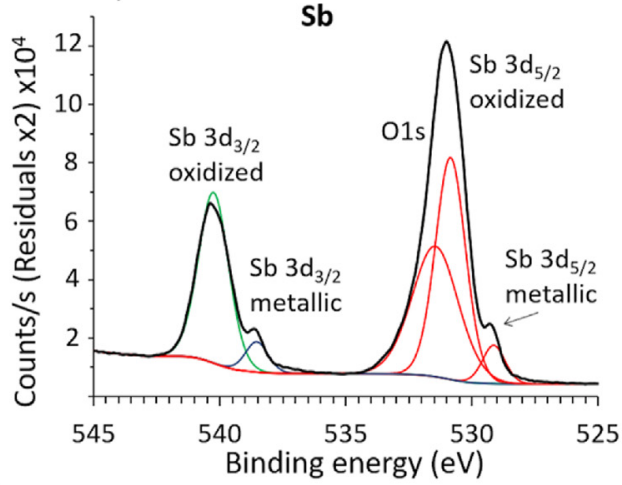

d)

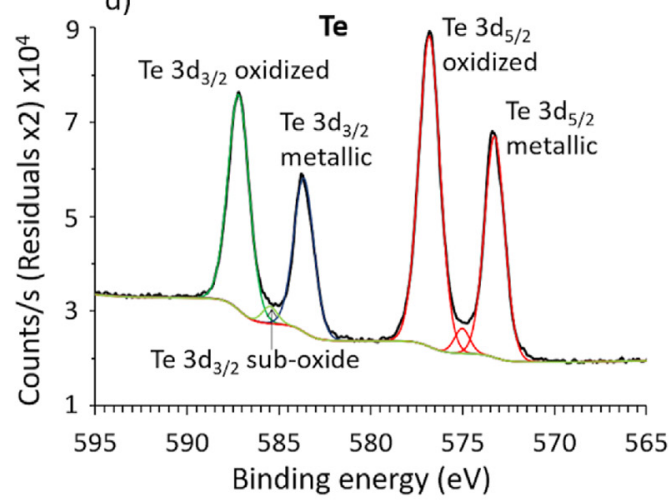

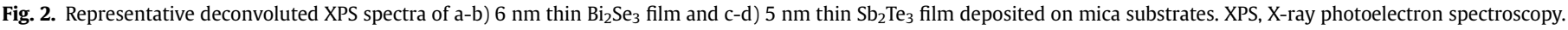

Table 1

Comparison of the chemical compositions of the $\mathrm{Bi}_{2} \mathrm{Se}_{3}$ and $\mathrm{Sb}_{2} \mathrm{Te}_{3}$ source materials and ultrathin films deposited on mica substrates revealed by the XPS measurements.

\begin{tabular}{|c|c|c|c|c|c|}
\hline \multirow[t]{2}{*}{ Chemical element } & $\mathrm{Bi}_{2} \mathrm{Se}_{3}$ source material & $\mathrm{Bi}_{2} \mathrm{Se}_{3} 6 \mathrm{~nm}$ thin film on mica & Chemical element & $\mathrm{Sb}_{2} \mathrm{Te}_{3}$ source material & $\mathrm{Sb}_{2} \mathrm{Te}_{3} 5 \mathrm{~nm}$ thin film \\
\hline & at $\%$ & at $\%$ & & at $\%$ & at $\%$ \\
\hline $\mathrm{Bi}$ & 37.1 & 36.7 & $\mathrm{Sb}$ & 41.6 & 44.9 \\
\hline Se & 62.9 & 63.3 & $\mathrm{Te}$ & 58.4 & 55.1 \\
\hline
\end{tabular}
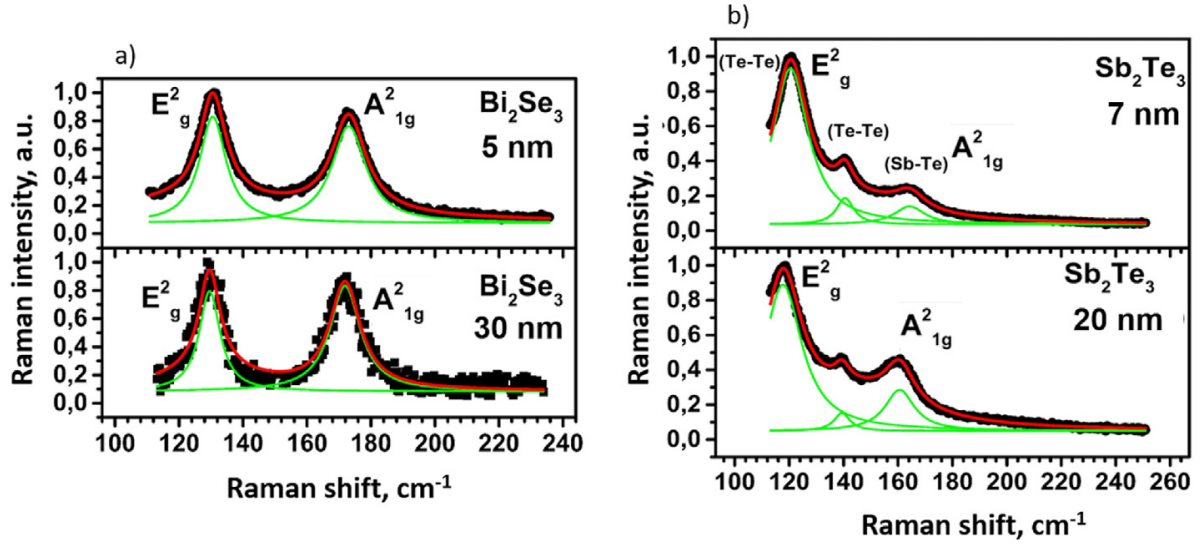

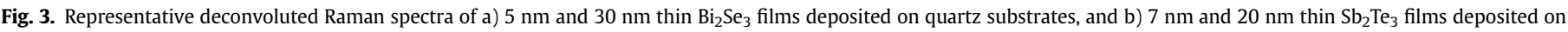
mica substrates.

film deposited on graphene substrates. The XRD spectra of thicker $(20 \mathrm{~nm}) \mathrm{Bi}_{2} \mathrm{Se}_{3}$ and $\mathrm{Sb}_{2} \mathrm{Te}_{3}$ thin films are shown for the comparison.

The XRD analysis of the $\mathrm{Bi}_{2} \mathrm{Se}_{3}$ thin films spectra (Fig. 4 a) revealed the presence of peaks related the $(003 n)$ group and the absence of peaks characteristic for polycrystalline $\mathrm{Bi}_{2} \mathrm{Se}_{3}(015)$ and (1010) reflection planes for both $6 \mathrm{~nm}$ and $20 \mathrm{~nm}$ thin films (ref. code 00-033-0214 [28]). This indicates well-oriented growth of $\mathrm{Bi}_{2} \mathrm{Se}_{3}$, with crystallographic c-axis oriented perpendicularly to the 

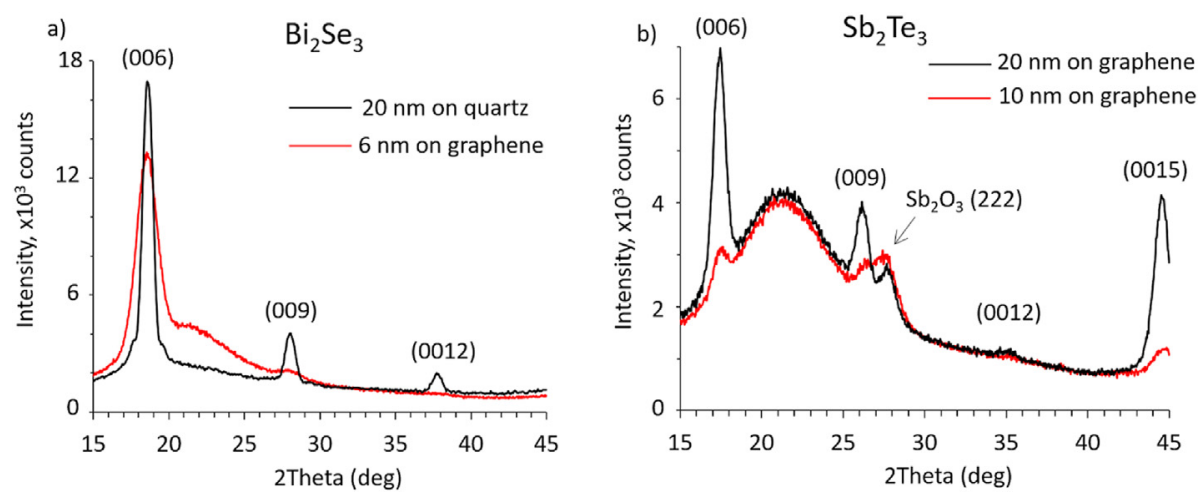

Fig. 4. Representative XRD spectra of a) $\mathrm{Bi}_{2} \mathrm{Se}_{3}$ and b) $\mathrm{Sb}_{2} \mathrm{Te}_{3}$ ultrathin films deposited on quartz and graphene substrates. XRD, X-ray diffraction.

substrate surface $[20,29]$. The intensity ratios for the peaks related to (006) and (009) reflection planes are 4.2 and 6.3 for the $20 \mathrm{~nm}$ thin film deposited on quartz and $6 \mathrm{~nm}$ thin film deposited on graphene, respectively, indicating a more uniform orientation of the ultrathin films grown on graphene in comparison with the ultrathin films grown on quartz, which is related to the epitaxial growth [20].

Similarly to the $\mathrm{Bi}_{2} \mathrm{Se}_{3}$, the most of peaks presented in the XRD spectra of the $\mathrm{Sb}_{2} \mathrm{Te}_{3}$ thin films (Fig. 4 b) were related to the (003n) group (ref. code 01-071-0393, calculated from ICSD 002084 using POWD-12++). Besides these peaks, a peak located at 2Theta $\sim 27.7$ deg was observed in both $\mathrm{Sb}_{2} \mathrm{Te}_{3}$ spectra. This peak may be attributed to the (222) reflection plane of the $\mathrm{Sb}_{2} \mathrm{O}_{3}$ oxide (ref. code 01-075-1565, calculated from ICSD 031102 using POWD-12++) and confirms the XPS data, where slight excess of Sb presented in the oxidized form on the surface of the $\mathrm{Sb}_{2} \mathrm{Te}_{3}$ thin film was identified.

\subsection{Electrical and thermoelectric characterization}

Despite the same deposition method and similar growth orientation and chemical composition, the in-plane electrical and thermoelectric properties of the deposited under identical conditions on mica and quartz substrates $\mathrm{Bi}_{2} \mathrm{Se}_{3}$ and $\mathrm{Sb}_{2} \mathrm{Te}_{3}$ ultrathin films differ (Table 2).

As it is seen fromTable 2, the ultrathin films deposited on quartz are few nm thicker and have higher Seebeck coefficients. However, because of the higher resistivity of these films, the resulting PF of these ultrathin films is lower than $\mathrm{Bi}_{2} \mathrm{Se}_{3}$ and $\mathrm{Sb}_{2} \mathrm{Te}_{3}$ ultrathin films deposited on mica. The reason for such a difference in properties may be mechanical and chemical defects of the quartz substrates, serving as multiple nucleation centers and resulting in formation of the film having more grain boundaries (boundaries between the coalesced nanoplates) than the ultrathin films deposited on mica, which is supported by the difference in intensity ratios of the XRD peaks, as well as by the previously reported structural investigation of the thicker films deposited on mica, quartz, and graphene $[18,20]$. While measurements of in-plane thermoelectric properties of ultrathin films deposited on graphene are challenging due to the high electrical and thermal conductivity of graphene, it is expected that because of the epitaxial growth they will be similar to the ultrathin films deposited on mica. Multiple grain boundaries reduce electrical conductance of the ultrathin films, but at the same time may serve as energy filters for the charge carriers, which results in an increase of the Seebeck coefficient. The following sections of the manuscript are focused on the in-detail investigation of the properties of showing better thermoelectric performance $\mathrm{Bi}_{2} \mathrm{Se}_{3}$ and $\mathrm{Sb}_{2} \mathrm{Te}_{3}$ ultrathin films deposited on mica substrates.

\subsection{Thickness-dependent electrical properties of ultrathin films deposited on mica}

Fig. 5 a illustrates temperature dependence of the resistivity of the $\mathrm{Bi}_{2} \mathrm{Se}_{3}$ and $\mathrm{Sb}_{2} \mathrm{Te}_{3}$ ultrathin films. The $\mathrm{Bi}_{2} \mathrm{Se}_{3}$ ultrathin film with thicknesses 6 and $15 \mathrm{~nm}$ exhibit metallic behavior typical for thin $\mathrm{Bi}_{2} \mathrm{Se}_{3}$ nanostructures (Fig. 5 a) [30]. For these thin films, the higher decrease rate of resistivity of the latter possibly indicates higher concentration of contributing to the conductivity defects as Se vacancies [31]. In turn, the resistivity of the $\mathrm{Bi}_{2} \mathrm{Se}_{3}$ ultrathin film with thickness $5 \mathrm{~nm}$ reaches its minimal value at temperature $257 \mathrm{~K}$ and then increases with decreasing temperature.

Such upturn in the resistivity of $5 \mathrm{~nm}$ thin $\mathrm{Bi}_{2} \mathrm{Se}_{3}$ film is consistent with some previous reports related to the opening of an energy band gap in very thin $\mathrm{Bi}_{2} \mathrm{Se}_{3}$ samples due to the quantum confinement effects resulting in reduction of electrical conductance at low temperatures [32,33]. While the precise determination of the band gaps of the $\mathrm{Bi}_{2} \mathrm{Se}_{3}$ ultrathin films was outside the scope of this work, the relation of the band gap value to the thickness of the thin film can be roughly evaluated by the estimation of the Fermi energy and the assumption that in the non-doped semiconductor the band gap energy approximately equals to the double of it. The Fermi energy can be estimated from the experimentally determined Seebeck coefficient by the simplified formula $\mathrm{E}_{\mathrm{F}} \approx \pi^{2} \mathrm{k}_{\mathrm{B}}^{2} \mathrm{~T} /$ 3eS [34], where $k_{B}$ is Boltzmann constant, $T$ is the background temperature, $\mathrm{e}$ is the elementary charge, and $\mathrm{S}$ is the absolute value of the Seebeck coefficient. As it is seen from Fig. 6, the Fermi energy of the $\mathrm{Bi}_{2} \mathrm{Se}_{3}$ thin films tends to increase with the decrease of the

Table 2

Representative comparison data between the properties of ultrathin $\mathrm{Bi}_{2} \mathrm{Se}_{3}$ and $\mathrm{Sb}_{2} \mathrm{Te}_{3}$ films deposited on mica and quartz substrates.

\begin{tabular}{|c|c|c|c|c|c|}
\hline Compound & Substrate & Film thickness, nm & Seebeck coefficient, $\mu \mathrm{V} \cdot \mathrm{K}^{-1}$ & Resistivity, $\Omega \cdot \mathrm{m}$ & $\mathrm{PF}, \mu \mathrm{W} \cdot \mathrm{K}^{-2} \cdot \mathrm{cm}^{-1}$ \\
\hline $\mathrm{Bi}_{2} \mathrm{Se}_{3}$ & mica & 6 & -55 & $1.23 \cdot 10^{-5}$ & 2.46 \\
\hline $\mathrm{Bi}_{2} \mathrm{Se}_{3}$ & quartz & 8 & -75 & $1.7 \cdot 10^{-4}$ & 0.33 \\
\hline $\mathrm{Sb}_{2} \mathrm{Te}_{3}$ & mica & 7 & 132 & $0.8 \cdot 10^{-5}$ & 23 \\
\hline $\mathrm{Sb}_{2} \mathrm{Te}_{3}$ & quartz & 10 & 154 & $2.1 \cdot 10^{-5}$ & 11 \\
\hline
\end{tabular}

$\mathrm{PF}$, power factor. 
a)

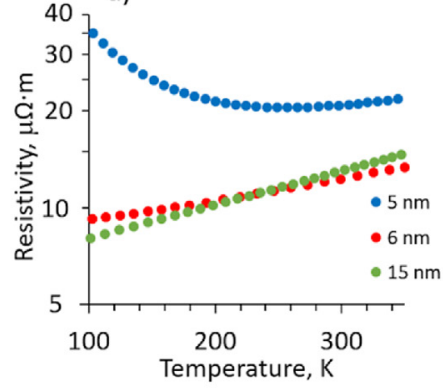

d)

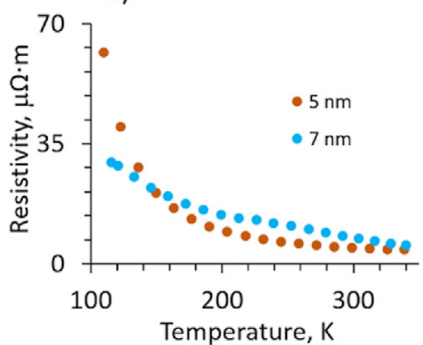

b)

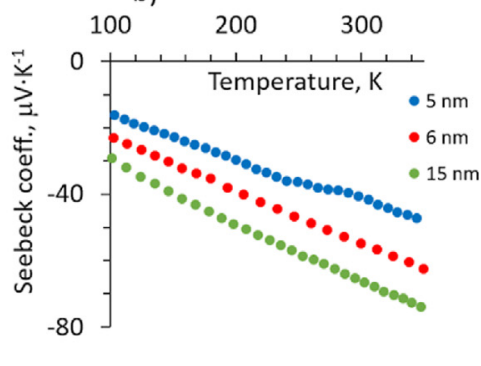

e)

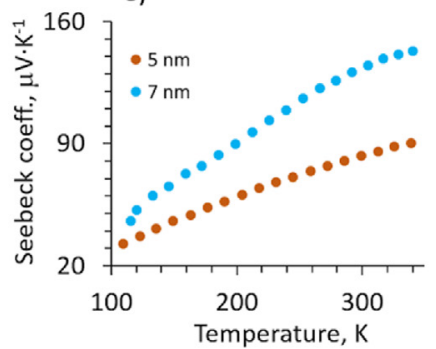

c)

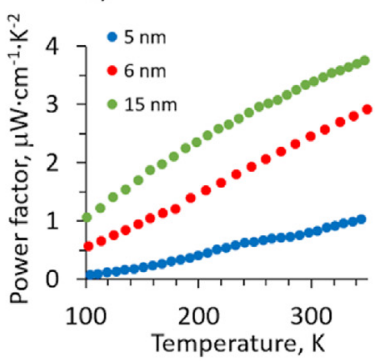

f)

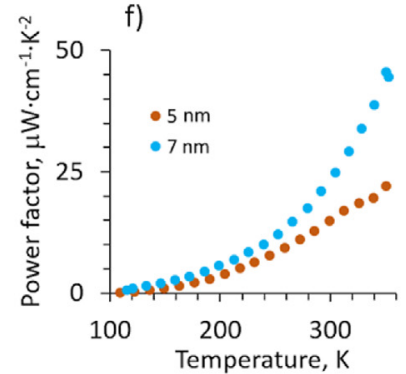

Fig. 5. Temperature dependencies of resistivity, Seebeck coefficient and $P F \mathrm{Bf}_{2} \mathrm{Se}_{3}(\mathrm{a}-\mathrm{c})$ and $\mathrm{Sb}_{2} \mathrm{Te}_{3}(\mathrm{~d}-\mathrm{f})$ ultrathin films of different thicknesses. $\mathrm{PF}$, power factor.

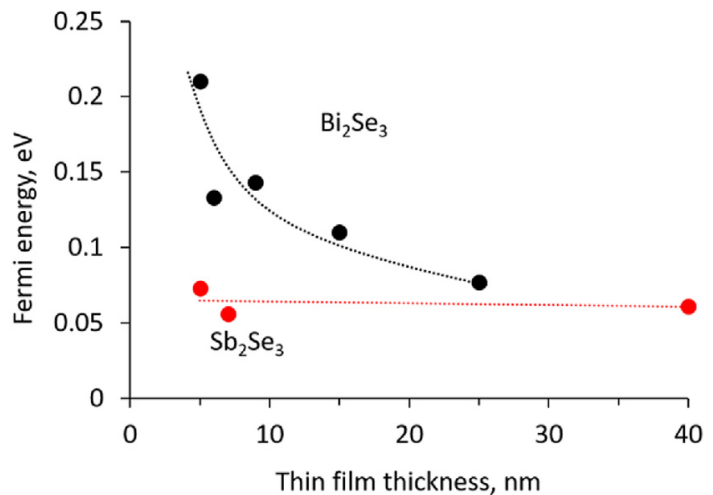

Fig. 6. Estimated values of the Fermi level for deposited on mica substrates $\mathrm{Bi}_{2} \mathrm{Se}_{3}$ and $\mathrm{Sb}_{2} \mathrm{Te}_{3}$ thin films of different thicknesses.

film thickness, proving the influence of the film thickness on the band gap size.

In contrast with the $\mathrm{Bi}_{2} \mathrm{Se}_{3}$ ultrathin films, the $5 \mathrm{~nm}$ and $7 \mathrm{~nm}$ thin $\mathrm{Sb}_{2} \mathrm{Te}_{3}$ showed the semiconductor type of conductivity (Fig. 5 d), with $5 \mathrm{~nm}$ thin film showing more pronounced temperaturedependent increase of resistivity and at a higher rate than $7 \mathrm{~nm}$ thin film. Accordingly to Hinsche et al. [14], such behavior of the resistivity may be attributed to significant contribution of surface states to the total conductivity of the thin films, whose hole concentration is in the order of $10^{18} \mathrm{~cm}^{-3}$. Increase of the Fermi level with the reduction of the film thickness was not observed for the 5-7 nm Sb $\mathrm{Te}_{3}$ ultrathin films, which is in agreement with Osterhage et al. [10] which proposed opening of the hybridization gap in $\mathrm{Sb}_{2} \mathrm{Te}_{3}$ when its thickness is reduced below $4 \mathrm{~nm}$.

\subsection{The Seebeck coefficient and power factor of the ultrathin films deposited on mica}

At $300 \mathrm{~K}$, the Seebeck coefficient of the $\mathrm{Bi}_{2} \mathrm{Se}_{3}$ ultrathin films varied from $-67 \mu \mathrm{V} \mathrm{K}^{-1}$ for $15 \mathrm{~nm}$ thick film to $-40 \mu \mathrm{V} \mathrm{K}^{-1}$ for $5 \mathrm{~nm}$ thick film (Fig. 5b). Negative values of Seebeck coefficients indicate n-type of conductivity of $\mathrm{Bi}_{2} \mathrm{Se}_{3}$. The PF calculated for $300 \mathrm{~K}$ varied from $3.4 \mu \mathrm{W} \mathrm{K} \mathrm{K}^{-2} \mathrm{~cm}^{-1}$ for $15 \mathrm{~nm}$ thick film to $0.8 \mu \mathrm{W} \mathrm{K} \mathrm{cm}^{-1}$ for $5 \mathrm{~nm}$ thick film. These values are comparable with the values obtained for the MBE-grown $\mathrm{Bi}_{2} \mathrm{Se}_{3}$ thin films $\left(\mathrm{S}=-85 \mu \mathrm{V} \mathrm{K} \mathrm{K}^{-1}\right.$ and $\mathrm{PF}=4 \mu \mathrm{W} \mathrm{K} \mathrm{K}^{-2} \mathrm{~cm}^{-1}$ for $15 \mathrm{~nm}$ thin film and $\mathrm{S}=-64.6 \mu \mathrm{V} \mathrm{K}^{-1}$ and $\mathrm{PF}=1.4 \mu \mathrm{W} \mathrm{K}^{-2} \mathrm{~cm}^{-1}$ for $5 \mathrm{~nm}$ thin film) [13] and indicate usability of our PVD method for obtaining of high-quality $\mathrm{Bi}_{2} \mathrm{Se}_{3}$ ultrathin films. For the $\mathrm{Sb}_{2} \mathrm{Te}_{3}$ ultrathin films, Seebeck coefficients were positive, indicating p-type conductivity as is expected for this material. $7 \mathrm{~nm}$ thin film showed significantly higher Seebeck coefficient than the $5 \mathrm{~nm}$ thin film $\left(\mathrm{S}=130 \mu \mathrm{V} \mathrm{K}^{-1} \mathrm{vs} . \mathrm{S}=82 \mu \mathrm{V} \mathrm{K}^{-1}\right)$. The calculated $\mathrm{PF}$ for $7 \mathrm{~nm}$ and $5 \mathrm{~nm}$ thin $\mathrm{Sb}_{2} \mathrm{Te}_{3}$ films were $23 \mu \mathrm{W} \mathrm{K} \mathrm{cm}^{-1}$ and $15 \mu \mathrm{W} \mathrm{K} \mathrm{K}^{-2} \mathrm{~cm}^{-1}$, respectively. These values are comparable with ones reported for $\sim 1 \mu \mathrm{m}$ thick $\mathrm{Sb}_{2} \mathrm{Te}_{3}$ thin films grown by $\operatorname{MBE}\left(\mathrm{S}=130 \mu \mathrm{V} \mathrm{K} \mathrm{K}^{-1}, \mathrm{PF}=29 \mu \mathrm{W} \mathrm{K} \mathrm{K}^{-2} \mathrm{~cm}^{-1}\right)$ [35], co-evaporation technique $\left(\mathrm{S}=160 \mu \mathrm{V} \mathrm{K}^{-1}, \mathrm{PF}=20 \mu \mathrm{W} \mathrm{K} \mathrm{K}^{-2} \mathrm{~cm}^{-1}\right)$ [36], and bulk $\mathrm{Sb}_{2} \mathrm{Te}_{3}$ grown by the Bridgman method $\left(\mathrm{S}=79 \mu \mathrm{V} \mathrm{K}^{-1}, \mathrm{PF}=30 \mu \mathrm{W} \mathrm{K} \mathrm{K}^{-2} \mathrm{~cm}^{-1}\right.$ ) [35]. There is a lack of experimental data on thermoelectrical properties on the ultrathin (below $30 \mathrm{~nm}$ ) $\mathrm{Sb}_{2} \mathrm{Te}_{3}$ films; however, accordingly to the theoretical studies, the significant difference in Seebeck coefficients of $5 \mathrm{~nm}$ and $7 \mathrm{~nm}$ thin $\mathrm{Sb}_{2} \mathrm{Te}_{3}$ films may be related to the larger contribution of topological conductive surface states in thinner films [14]. For easier reading, Table 3 summarizes Seebeck coefficient and PF of the thin films obtained in this work and reported by other research groups, including data for bulk $\mathrm{Bi}_{2} \mathrm{Se}_{3}$ and $\mathrm{Sb}_{2} \mathrm{Te}_{3}$ materials.

Temperature dependence of experimentally determined Seebeck coefficients and estimated $\mathrm{PF}$ of $\mathrm{Bi}_{2} \mathrm{Se}_{3}$ and $\mathrm{Sb}_{2} \mathrm{Te}_{3}$ ultrathin films of different thicknesses are shown in Fig. 5 b,c,e,f. $\mathrm{All} \mathrm{Bi}_{2} \mathrm{Se}_{3}$ films showed quasilinear decrease of the Seebeck coefficient and PF with the decrease of temperature (Fig. 5 b,c), which indicates prevailing degenerate electron state [13]. Determined from the slopes of the PF curves decrease rates showed clear dependence of $\mathrm{PF}$ on the ultrathin films thickness, and ranged from $0.0113 \mu \mathrm{W} \mathrm{cm} \mathrm{cm}^{-1} \mathrm{~K}^{-2}$ per $\mathrm{K}$ for $15 \mathrm{~nm}$ thin film down to $0.0038 \mu \mathrm{W} \mathrm{cm}{ }^{-1} \mathrm{~K}^{-2}$ per $\mathrm{K}$ for $5 \mathrm{~nm}$ thin film. Lower PF decrease rates of thinner $\mathrm{Bi}_{2} \mathrm{Se}_{3}$ films indicate their better applicability for 
Table 3

Comparison between the Seebeck coefficients and $\mathrm{PF}$ of $\mathrm{Bi}_{2} \mathrm{Se}_{3}$ and $\mathrm{Sb}_{2} \mathrm{Te}_{3}$ thin films obtained in this work and by other research groups.

\begin{tabular}{|c|c|c|c|}
\hline Sample & Seebeck coefficient, $\mu \mathrm{V} \cdot \mathrm{K}^{-1}$ & $\mathrm{PF}, \mu \mathrm{W} \cdot \mathrm{K}^{-2} \cdot \mathrm{cm}^{-1}$ & Research group \\
\hline $5 \mathrm{~nm}$ thin $\mathrm{Bi}_{2} \mathrm{Se}_{3}$ film & -40 & 0.8 & this work \\
\hline $6 \mathrm{~nm}$ thin $\mathrm{Bi}_{2} \mathrm{Se}_{3}$ film & -55 & 2.45 & this work \\
\hline $15 \mathrm{~nm}$ thin $\mathrm{Bi}_{2} \mathrm{Se}_{3}$ film & -67 & 3.5 & this work \\
\hline MBE-grown $5 \mathrm{~nm}$ thin $\mathrm{Bi}_{2} \mathrm{Se}_{3}$ film & -64.6 & 1.4 & Guo et al. [13] \\
\hline MBE-grown $15 \mathrm{~nm}$ thin $\mathrm{Bi}_{2} \mathrm{Se}_{3}$ film & -85 & 4.0 & Guo et al. [13] \\
\hline Bulk $\mathrm{Bi}_{2} \mathrm{Se}_{3}$ (Bridgman method) & -59 & 9.4 & Navrátil et al. [37] \\
\hline $5 \mathrm{~nm}$ thin $\mathrm{Sb}_{2} \mathrm{Te}_{3}$ film & 82 & 15 & this work \\
\hline $7 \mathrm{~nm}$ thin $\mathrm{Sb}_{2} \mathrm{Te}_{3}$ film & 130 & 23 & this work \\
\hline MBE-grown $1 \mu \mathrm{m}$ thin $\mathrm{Sb}_{2} \mathrm{Te}_{3}$ film & 130 & 29 & Peranio et al. [35] \\
\hline Co-evaporated $1 \mu \mathrm{m}$ thin $\mathrm{Sb}_{2} \mathrm{Te}_{3}$ film & 160 & 20 & Huang et al. [36] \\
\hline Bulk $\mathrm{Sb}_{2} \mathrm{Te}_{3}$ (Bridgman method) & 79 & 30 & Peranio et al. [35] \\
\hline
\end{tabular}

MBE, molecular beam epitaxy.

wide-range temperature applications. Observed for the considered temperature range systematic decrease of the Seebeck coefficient and PF with the decrease of $\mathrm{Bi}_{2} \mathrm{Se}_{3}$ ultrathin film thickness is consistent with the previous report on thermoelectrical properties of $\mathrm{Bi}_{2} \mathrm{Se}_{3} \mathrm{MBE}$ thin films with thicknesses 5-30 nm [13]. It can be attributed to the increase of the contribution of Dirac-like topological surface states, whose linear dispersion is not optimal for the increase of the Seebeck coefficient [13]. The possible measures for improvement of the power factor of ultrathin films may include further decrease of the film thickness below $5 \mathrm{~nm}$ to completely gap the surface states, as well as tuning of the Fermi level by doping. Temperature dependencies of Seebeck coefficient of $\mathrm{Sb}_{2} \mathrm{Te}_{3}$ ultrathin films showed slight deviations from linear behavior, but their PF exhibited power-law increase (especially for the $7 \mathrm{~nm}$ thin $\mathrm{Sb}_{2} \mathrm{Te}_{3}$ film) with the increase of temperature (Fig. 5 e,f). The nonlinear behavior of Seebeck coefficient and PF of ultrathin $\mathrm{Sb}_{2} \mathrm{Te}_{3}$ films is consistent with the remarkable contribution of topological surface states of the nanoscale $\mathrm{Sb}_{2} \mathrm{Te}_{3}$ with charge carrier concentrations in the order $10^{18}-10^{19}$ [14]. However, further experimental work is required for clarification of the observed dependencies. Significant increase of the $\mathrm{PF}$ of the $7 \mathrm{~nm}$ thin $\mathrm{Sb}_{2} \mathrm{Te}_{3}$ film above the room temperature makes it attractive for application in thermoelectrical devices for domestic waste heat conversion.

Showing the best $\mathrm{PF} \mathrm{Bi}_{2} \mathrm{Se}_{3}$ and $\mathrm{Sb}_{2} \mathrm{Te}_{3}$ ultrathin films of $15 \mathrm{~nm}$ and $7 \mathrm{~nm}$ thickness, respectively, were tested in a prototype of twoleg TEG as described in the Experimental section. a)

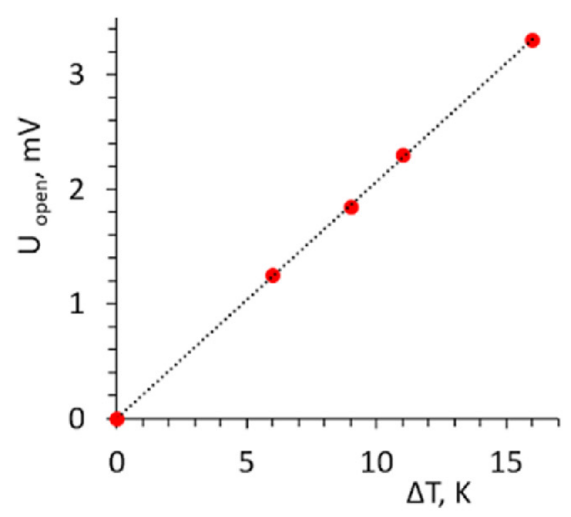

c)

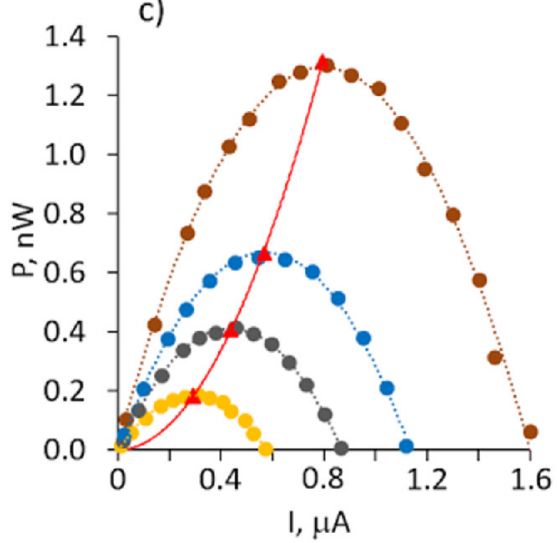

b)

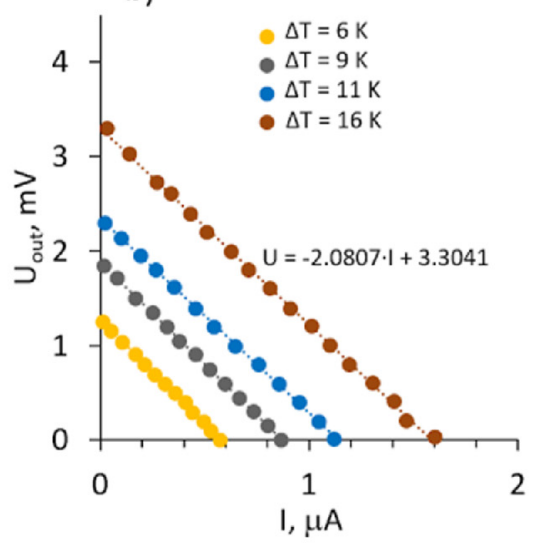

d)

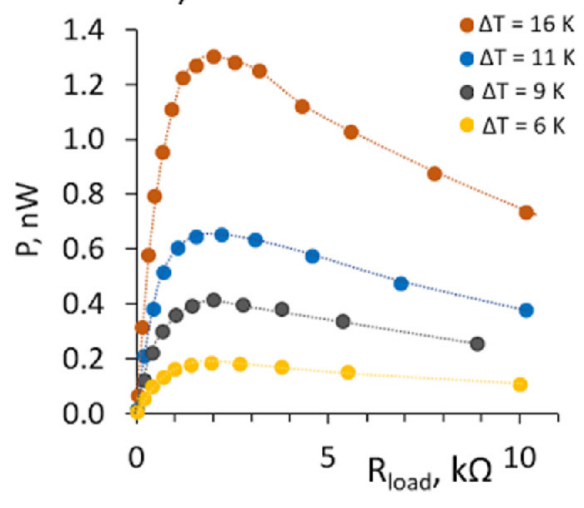

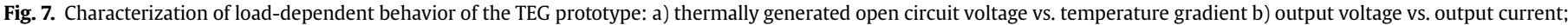
c) output power vs. output current; red triangles represent maximal power for each temperature gradient; d) output power vs. external load. 
Performance of the TEG prototype was characterized by measuring the load-dependence behavior [38]. The open circuit output voltage generated by the TEG showed linear dependence on the temperature gradient (Fig. 7 a) that can be described by function $\mathrm{U}_{\text {out }}[\mathrm{mV}]=0.2 \cdot \Delta \mathrm{T}[\mathrm{K}]$. This result is roughly 2 times lower in comparison with the $\mathrm{U}_{\text {open }}(\Delta \mathrm{T})$ function obtained for commercial thermoelectric module TEC1-12707 $\left(\mathrm{U}_{\text {open }}[\mathrm{mV}]=53.17 \cdot \Delta \mathrm{T}\right.$ for 127 leg couples, which equals $U_{\text {open }}[\mathrm{mV}]=0.42 \cdot \Delta \mathrm{T}$ per one leg pair) [38]. Most likely, the poorer performance of the demonstrated prototype in comparison with the commercial device is related to the heat dissipation at the ultrathin film-mica substrate interface and in the electrical contacts to the ultrathin films, which should be optimized in future. The output voltage vs. output current of the TEG at different external loads and temperature gradients is shown in Fig. 7 b. Dependencies of output voltage vs. output current are linear and of equal slope, proving stable operation of the device and allowing to extract the thermopower and internal resistance of the TEG from the linear fittings (Fig. 7 b), as well as to calculate the output power vs. output current (Fig. 7 c) and vs. the external load (Fig. 7 d) (Table 4). It was found that the maximal output power produced by the TEG prototype shows power-law increase with the increase of the temperature gradient (Fig. 7 c), which makes these devices attractive for applications involving low temperature gradients, for example, for domestic waste heat conversion. As the maximal power generated by the two-leg TEG prototype was in the range of $\mathrm{nW}$ for the nanosized cross-section, the comparison of its performance with the performance of the commercially available thermoelectric module was performed per cross-section unit. The maximal powers per cross-section area generated by the two-leg TEG prototype and 127 leg couple TEC1-12707 [38] were found to be $1.2 \mathrm{~mW} \mathrm{~cm}^{-2}$ and $6.25 \mathrm{~mW} \mathrm{~cm} \mathrm{~cm}^{-2}$, respectively, indicating a high potential of the demonstrated TEG prototype for further development and application in domestic waste heat conversion devices.

As it can be seen from Table 4, the main drawback of the developed two-leg TEG prototype is high internal resistance in comparison with the bulk materials because of the very high length-to-cross-section ratios of the ultrathin films. This puts limitation to the resistance of the external devices as it is well known that power transfer between a voltage source and an external load is at its most efficient when the resistance of the load matches the internal resistance of the voltage source. However, such TEGs may find application for powering of potential devices having the resistance in the range $1-10 \mathrm{k} \Omega$ as their operation at such external loads is quite stable (Fig. 7 d). Comparison of the properties (measured at room temperature) of ultrathin films used for development of two-leg TEG prototype with the properties of the thin films used for development of the superlattice-based thin film thermoelectric modules, capable of producing a cooling flux of double that of the current state-of-the-art value [39]; however, not tested under different external loads is shown in Table 5.

As it is seen from the data in Table 5 and also supported by the research performed by other groups [40], the improvement of the thermoelectric efficiency of thin films may be achieved by consecutive deposition of different materials having the same type

Table 4

The main parameters of the ultrathin films-based two-leg TEG prototype.

\begin{tabular}{lllll}
\hline $\begin{array}{l}\text { Temperature } \\
\text { gradient, } \mathrm{K}\end{array}$ & $\begin{array}{l}\text { Thermopower, } \\
\mu \mathrm{V} / \mathrm{K}\end{array}$ & $\begin{array}{l}\text { Internal } \\
\text { resistance, } \Omega\end{array}$ & $\begin{array}{l}\text { Maximal output } \\
\text { power, } \mathrm{nW}\end{array}$ & $\begin{array}{l}\text { Optimal load } \\
\text { resistance, } \Omega\end{array}$ \\
\hline 6 & 204.9 & 2195 & 0.184 & 2188 \\
9 & 203.6 & 2158 & 0.406 & 2136 \\
11 & 205.5 & 2061 & 0.666 & 2057 \\
16 & 200.6 & 2081 & 1.316 & 2087 \\
\hline
\end{tabular}

Table 5

Comparison between properties of thin films synthesized in this work and reported by the other group.

\begin{tabular}{|c|c|c|c|c|}
\hline $\begin{array}{l}\text { Type of the } \\
\text { thin film }\end{array}$ & $\begin{array}{l}\text { Electrical } \\
\text { resistivity, } \\
\mu \Omega \cdot \mathrm{m}\end{array}$ & $\begin{array}{l}\text { Seebeck } \\
\text { coefficient, } \\
\mu \mathrm{V} \cdot \mathrm{K}^{-1}\end{array}$ & $\begin{array}{l}\mathrm{PF} \\
\mu \mathrm{W} \cdot \mathrm{K}^{-2} \cdot \mathrm{cm}^{-1}\end{array}$ & Reference \\
\hline $\begin{array}{l}\text { p-type } \mathrm{Bi}_{2} \mathrm{Te}_{3} / \\
\mathrm{Sb}_{2} \mathrm{Te}_{3}\end{array}$ & 10.2 & 238 & 55 & $\begin{array}{l}\text { Bulman } \\
\text { et al. [39] }\end{array}$ \\
\hline p-type $\mathrm{Sb}_{2} \mathrm{Te}_{3}$ & 7.5 & 132 & 23 & This work \\
\hline $\begin{array}{c}\text { n-type } \delta \text {-doped } \\
\mathrm{Bi}_{2} \mathrm{Te}_{3-\mathrm{x}} \mathrm{Se}_{\mathrm{x}}\end{array}$ & 13.7 & -276 & 56 & $\begin{array}{l}\text { Bulman } \\
\text { et al. [39] }\end{array}$ \\
\hline n-type $\mathrm{Bi}_{2} \mathrm{Se}_{3}$ & 13 & -67 & 3.5 & This work \\
\hline
\end{tabular}

of conductivity and similar crystal lattices, which is in the scope of the following work of our group.

\section{Conclusions}

In summary, the PVD method for obtaining of $\mathrm{Bi}_{2} \mathrm{Se}_{3}$ and $\mathrm{Sb}_{2} \mathrm{Te}_{3}$ ultrathin films of thicknesses $5-10-15 \mathrm{~nm}$ on different substrates as mica, fused quartz, and monolayer graphene has been developed. 5-7 nm thin $\mathrm{Sb}_{2} \mathrm{Te}_{3}$ films were synthesized for the first time. Deposited on mica $5-15 \mathrm{~nm}$ thin $\mathrm{Bi}_{2} \mathrm{Se}_{3}$ films and 5-7 nm thin $\mathrm{Sb}_{2} \mathrm{Te}_{3}$ films showed thermoelectrical properties comparable with MBE-grown thin films. $5 \mathrm{~nm}$ thin $\mathrm{Bi}_{2} \mathrm{Se}_{3}$ film showed pronounced unusual upturn in resistance at temperatures below $257 \mathrm{~K}$. These results are consistent with recent theoretical research gapping of topological surface states in $\mathrm{Bi}_{2} \mathrm{Se}_{3}$ thin films with thicknesses below $6 \mathrm{~nm}$, which may potentially result in enhancement of thermoelectrical efficiency of this material. However, the observed systematic decrease of the Seebeck coefficient and power factor with the decrease of thickness of the $\mathrm{Bi}_{2} \mathrm{Se}_{3}$ ultrathin films indicates necessity of additional downsizing measures for effective enhancement of thermoelectric properties of this material. In turn, $7 \mathrm{~nm}$ thin $\mathrm{Sb}_{2} \mathrm{Te}_{3}$ film showed significant thermoelectric properties, which are comparable with $1 \mu \mathrm{m}$-thick MBE-grown film. Performance of $15 \mathrm{~nm}$ thin $\mathrm{Bi}_{2} \mathrm{Se}_{3}$ film and $7 \mathrm{~nm}$ thin $\mathrm{Sb}_{2} \mathrm{Te}_{3}$ film was tested in the two-leg prototype of the TEG. It showed stable operation under different external loads and temperature gradients and performance comparable with the commercial thermoelectric module; however, because of the high internal resistance it was found useful for powering devices with resistances in the range $1-10 \mathrm{k} \Omega$. Potential routes for the improvement of the thermoelectric performance of the ultrathin films-based TEGs include replacement of the single ultrathin film with multilayered structures, the use of substrates with low thermal conductivity, and optimization of the electrical contacts to ultrathin films.

\section{Materials and methods}

\subsection{Deposition of ultrathin films}

The ultrathin films were deposited using a single-zone quartz tube furnace GCL-1100X (MTI Corp.). Bismuth (Bi) ( $\geq 99.99 \%$, CAS: 7440-69-9, Sigma Aldrich), selenium (Se) (99+, CAS: 7782-49-2, Emsure) and antimony telluride $\left(\mathrm{Sb}_{2} \mathrm{Te}_{3}\right)(99.999 \%$, CAS: $1327-50-$ 0 , Alfa Aesar) powders were used as source materials. Evaporation temperatures were $500{ }^{\circ} \mathrm{C}$ for $\mathrm{Bi}, 480^{\circ} \mathrm{C}$ for Se, and $415-420^{\circ} \mathrm{C}$ for $\mathrm{Sb}_{2} \mathrm{Te}_{3}$. The substrate - freshly cleaved natural mica sheets - of thickness $\sim 60 \mu \mathrm{m}$ (Agar Scientific) or fused quartz $2 \mathrm{~cm} \times 2 \mathrm{~cm} \mathrm{x}$ $1 \mathrm{~mm}$ (Agar Scientific) or grown by chemical vapor deposition and transferred to the quartz substrate monolayer graphene [29] was placed downstream from the source materials located in the central area of the furnace tube. After the placement of the source materials and the substrate, the furnace tube was ventilated with 
the nitrogen flow and pumped down to the base pressure of 150 mTorr, which was kept constant during the deposition process. The heating rate of the source materials was $48{ }^{\circ} \mathrm{C} / \mathrm{min}$. The maximal substrate temperature during the deposition process was $400{ }^{\circ} \mathrm{C}$ for deposition of $\mathrm{Bi}_{2} \mathrm{Se}_{3}$ selenide and $220{ }^{\circ} \mathrm{C}$ for deposition of $\mathrm{Sb}_{2} \mathrm{Te}_{3}$. The furnace was held at the maximal source materials evaporation temperature for 1-3 min for deposition of $\mathrm{Bi}_{2} \mathrm{Se}_{3}$ of different thicknesses, followed by natural cooling down to the room temperature. For obtaining of the ultrathin $\mathrm{Sb}_{2} \mathrm{Te}_{3}$ films, after reaching the maximal temperature in the center of the furnace hot zone, the substrate and the source material were rapidly cooled down by extracting the quartz furnace tube out of the hot zone of the furnace and simultaneous filling it with nitrogen up to the atmospheric pressure.

\subsection{Characterization}

Morphology, thickness, and structure of the deposited ultrathin films were inspected using the field emission SEM Hitachi S-4800, AFM Asylum Research MFP-3D, and X-ray diffraction spectroscopy (powder diffractometer X'PERT MRD with $\mathrm{Cu}_{\alpha}$ radiation source). XPS analyses were carried out using the ThermoFisher ESCALAB $\mathrm{Xi}^{+}$ instrument using a monochromatic $\mathrm{Al} \mathrm{K}_{\alpha} \mathrm{X}$-ray source. The instrument binding-energy scale was calibrated to give a binding energy at $932.6 \mathrm{eV}$ for $\mathrm{Cu} 2 \mathrm{p}_{3 / 2}$ line of freshly etched metallic copper. The charge compensation system was used on all nonconductive specimen samples. The surface of each sample was irradiated with a flood of electrons to produce a nearly neutral surface charge. The spectra were recorded by using an X-ray beam size $900 \times 10 \mu \mathrm{m}$, a pass energy of $20 \mathrm{eV}$, and step size $0.1 \mathrm{eV}$. Data from all materials have been referenced using the main signal of the carbon $1 \mathrm{~s}$ spectrum assigned to occur at $285.0 \mathrm{eV}$. The carbon $1 \mathrm{~s}$ spectrum was collected using high energy resolution settings. Raman spectra were recorded at the room temperature using scanning laser confocal micro-Raman spectrometer Confotec NR 500 with $785 \mathrm{~nm}$ excitation wavelength, $0.86 \mathrm{~mW}$ power, and $100 \mathrm{x}$ objective. The accumulation time of the signal for each spectrum was $10 \mathrm{~s}$. The laser beam diameter was about $600 \mathrm{~nm}$. Raman spectra were registered using $1800 \mathrm{l} / \mathrm{mm}$ grating, and spectral resolution $\sim 0.2 \mathrm{~cm}^{-1}$. Throughout these measurements, the edge filter cutting at $\sim 85 \mathrm{~cm}^{-1}$ was used.

Electrical and thermoelectric characterization: Resistance and Seebeck coefficients of the ultrathin films were performed using thermal transport option of Physical Property Measurement System DynaCool9T (Quantum Design) in 4-point configuration for elimination of the influence of contact resistance. For determination of the Seebeck coefficient, the temperature difference between the sides of the ultrathin films did not exceed 3\% from the measurement temperature.

\subsection{Fabrication and testing of a TEG prototype}

For the fabrication of the TEG prototype consisting of one p-type and one n-type leg, the $5 \mathrm{~mm} \times 15 \mathrm{~mm}$ large stripes of $\mathrm{Bi}_{2} \mathrm{Se}_{3}$ and $\mathrm{Sb}_{2} \mathrm{Te}_{3}$ ultrathin films deposited on mica were used. $5 \mathrm{~mm} \times 5 \mathrm{~mm}$ gold contacts (thickness $\sim 100 \mathrm{~nm}$ ) were deposited over the sides of the thermoelectric stripes using the thermal deposition method (SIDRABE SAF EM sputtering vacuum system), leaving $5 \mathrm{~mm} \times 5 \mathrm{~mm}$ of the ultrathin film between the electrodes free. Copper wires were attached to the gold electrodes using electrically conductive adhesive (EPO-TEK $® \mathrm{H} 20 \mathrm{E})$. Thermally generated by the TEG prototype voltage was measured using a homemade device for thermoelectrical measurements [20] under temperature gradients from 6 up to $12 \mathrm{~K}$, as open circuit and under different (from $1 \mathrm{k} \Omega$ up to $100 \mathrm{k} \Omega$ ) external loads.

\section{Credit author statement}

Jana Andzane: Investigation, Formal analysis, Visualization, Writing - original draft Andrei Felsharuk: Investigation, Methodology, Validation Anatolijs Sarakovskis: Investigation, Formal analysis, Visualization, Writing - original draft Uldis Malinovskis: Investigation, Formal analysis E. Kauranens: Investigation, Formal analysis, Visualization Mikhael Bechelany: Investigation, Formal analysis Kiryl A. Niherysh: Investigation, Formal analysis, Visualization Ivan V. Komissarov: Conceptualization, Supervision Donats Erts: Conceptualization, Methodology, Supervision, Writing - review \& editing

\section{Declaration of competing interest}

The authors declare that they have no known competing financial interests or personal relationships that could have appeared to influence the work reported in this paper.

\section{Acknowledgements}

This work was supported by the European Regional Development Fund (ERDF) project No 1.1.1.1/16/A/257. J. A. acknowledges the ERDF project No.1.1.1.2/1/16/037. Institute of Solid State Physics, University of Latvia, Latvia as the Center of Excellence has received funding from the European Union's Horizon 2020 Framework Programme H2020-WIDESPREAD-01-2016-2017-TeamingPhase2 under grant agreement No. 739508, project CAMART ${ }^{2}$.

The raw/processed data required to reproduce these findings cannot be shared at this time as the data also form a part of an ongoing study.

\section{Appendix A. Supplementary data}

Supplementary data to this article can be found online at https://doi.org/10.1016/j.mtener.2020.100587.

\section{References}

[1] J.R. Sootsman, D.Y. Chung, M.G. Kanatzidis, New and old concepts in thermoelectric materials, Angew. Chem. Int. Ed. 48 (2009) 8616-8639, https:// doi.org/10.1002/anie.200900598.

[2] Y.L. Chen, J.G. Analytis, J. Chu, Z.K. Liu, S. Mo, X.L. Qi, H.J. Zhang, D.H. Lu, X. Dai, Z. Fang, S.C. Zhang, I.R. Fisher, Z. Hussain, Z. Shen, Experimental realization of a three-dimensional topological insulator, $\mathrm{Bi}_{2} \mathrm{Te}_{3}$, science 178 (2009) 1-4, https://doi.org/10.1126/science.1173034.

[3] H. Zhang, C.X. Liu, X.L. Qi, X. Dai, Z. Fang, S.C. Zhang, Topological insulators in $\mathrm{Bi}_{2} \mathrm{Se}_{3}, \mathrm{Bi}_{2} \mathrm{Te}_{3}$ and $\mathrm{Sb}_{2} \mathrm{Te}_{3}$ with a single Dirac cone on the surface, Nat. Phys. 5 (2009) 438-442, https://doi.org/10.1038/nphys1270.

[4] Q. Liu, C.X. Liu, C. Xu, X.L. Qi, S.C. Zhang, Magnetic impurities on the surface of a topological insulator, Phys. Rev. Lett. 102 (2009) 1-4, https://doi.org/ 10.1103/PhysRevLett.102.156603.

[5] L. Hicks, M.S. Dresselhaus, Thermoelectric figure of merit of a one-dimensional semiconductor, Phys. Rev. B 47 (1993) 8-11, https://doi.org/10.1103/ PhysRevB.47.16631.

[6] L. Hicks, M.S. Dresselhaus, Effect of quantum-well structures on the thermoelectric figure of merit, Phys. Rev. B 47 (1993) 12727, https://doi.org/10.1103/ PhysRevB.47.12727.

[7] K. Pal, S. Anand, U.V. Waghmare, Thermoelectric properties of materials with nontrivial electronic topology, J. Mater. Chem. C 3 (2015) 12130-12139, https://doi.org/10.1039/c5tc02344k.

[8] P. Ghaemi, R.S.K. Mong, J.E. Moore, In-plane transport and enhanced thermoelectric performance in thin films of the topological insulators $\mathrm{Bi}_{2} \mathrm{Te}_{3}$ and $\mathrm{Bi}_{2} \mathrm{Se}_{3}$, Phys. Rev. Lett. 105 (2010) 1-4, https://doi.org/10.1103/ PhysRevLett.105.166603. 
[9] M. Tahir, A. Manchon, U. Schwingenschlögl, Enhanced thermoelectric power in ultrathin topological insulators with magnetic doping, J. Appl. Phys. 116 (2014), https://doi.org/10.1063/1.4894283.

[10] H. Osterhage, J. Gooth, B. Hamdou, P. Gwozdz, R. Zierold, K. Nielsch, Thermoelectric properties of topological insulator $\mathrm{Bi}_{2} \mathrm{Te}_{3}, \mathrm{Sb}_{2} \mathrm{Te}_{3}$, and $\mathrm{Bi}_{2} \mathrm{Se}_{3}$ thin film quantum wells, Appl. Phys. Lett. 105 (2014), https://doi.org/10.1063/ 1.4896680 .

[11] M. Samanta, K. Pal, U.V. Waghmare, K. Biswas, Intrinsically low thermal conductivity and high carrier mobility in dual topological quantum material, n-type BiTe, Angew. Chem. 132 (2020) 4852-4859, https://doi.org/10.1002/ ange.202000343.

[12] J. Zhang, X. Feng, Y. Xu, M. Guo, Z. Zhang, Y. Ou, Y. Feng, K. Li, H. Zhang, L. Wang, X. Chen, Z. Gan, S.C. Zhang, K. He, X. Ma, Q.K. Xue, Y. Wang, Disentangling the magnetoelectric and thermoelectric transport in topological insulator thin films, Phys. Rev. B Condens. Matter 91 (2015) 1-7, https:// doi.org/10.1103/PhysRevB.91.075431.

[13] M. Guo, Z. Wang, Y. Xu, H. Huang, Y. Zang, C. Liu, W. Duan, Z. Gan, S.C. Zhang,

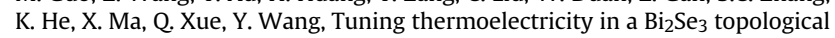
insulator via varied film thickness, New J. Phys. 18 (2016), https://doi.org/ 10.1088/1367-2630/18/1/015008.

[14] N.F. Hinsche, S. Zastrow, J. Gooth, L. Pudewill, R. Zierold, F. Rittweger, T. Rauch, J. Henk, K. Nielsch, I. Mertig, Impact of the topological surface state on the thermoelectric transport in $\mathrm{Sb}_{2} \mathrm{Te}_{3}$ thin films, ACS Nano 9 (2015) 4406-4411, https://doi.org/10.1021/acsnano.5b00896.

[15] H. Li, X. Chen, Y. Zhang, K. He, J. Cao, W. Zheng, C.-L. Song, Y. Chen, C.-Z. Chang, D. Wu, W. Dang, L.-L. Wang, K. Wang, J.-F. Jia, H. Peng, Z. Fang, Z. Liu, X. Dai, W.-Y. Shan, S.-Q. Shen, X.-L. Qi, Q. Niu, X.-C. Ma, S.-C. Zhang, Q.-K. Xue, Controlled synthesis of topological insulator nanoplate arrays on mica, J. Am. Chem. Soc. 134 (2012) 6132-6135. http://www.nature.com/doifinder/10. 1038/nphys1689\%0Apapers3:/publication/doi/10.1021/ja3021395.

[16] L. Kou, B. Yan, F. Hu, S.C. Wu, T.O. Wehling, C. Felser, C. Chen, T. Frauenheim, Graphene-based topological insulator with an intrinsic bulk band gap above room temperature, Nano Lett. 13 (2013) 6251-6255, https://doi.org/10.1021/ nl4037214.

[17] S. Singh, S. Kim, W. Jeon, K.P. Dhakal, J. Kim, S. Baik, Graphene grain sizedependent synthesis of single-crystalline $\mathrm{Sb}_{2} \mathrm{Te}_{3}$ nanoplates and the interfacial thermal transport analysis by Raman thermometry, Carbon N. Y 153 (2019) 164-172, https://doi.org/10.1016/j.carbon.2019.07.017.

[18] J. Andzane, L. Britala, E. Kauranens, A. Neciporenko, M. Baitimirova, S. LaraAvila, S. Kubatkin, M. Bechelany, D. Erts, Effect of graphene substrate type on formation of $\mathrm{Bi}_{2} \mathrm{Se}_{3}$ nanoplates, Sci. Rep. 9 (2019) 1-8, https://doi.org/ 10.1038/s41598-019-41178-1.

[19] J. Andzane, G. Kunakova, S. Charpentier, V. Hrkac, L. Kienle, M. Baitimirova, T. Bauch, F. Lombardi, D. Erts, Catalyst-free vapour-solid technique for deposition of $\mathrm{Bi}_{2} \mathrm{Te}_{3}$ and $\mathrm{Bi}_{2} \mathrm{Se}_{3}$ nanowires/nanobelts with topological insulator properties, Nanoscale 7 (2015) 15935-15944, https://doi.org/10.1039/ c5nr04574f.

[20] J. Andzane, K. Buks, M.N. Strakova, M. Zubkins, M. Bechelany, M. Marnauza, M. Baitimirova, D. Erts, Structure and doping determined thermoelectric properties of $\mathrm{Bi}_{2} \mathrm{Se}_{3}$ thin films deposited by vapour-solid technique, IEEE Trans. Nanotechnol. 18 (2019) 948-954, https://doi.org/10.1109/ TNANO.2019.2939862.

[21] N. Sirota, Chemical Bonds in Solids, Consultants bureau, New York-London, 1972, https://doi.org/10.1007/978-1-4684-1686-2 n.d

[22] Y. Luo, Bond dissociation energies Yu-ran Luo table 1, Bond dissociation energies in diatomic molecules, CRC Handb. Chem. Phys (2009) 65-98. https:// notendur.hi.is/agust/rannsoknir/papers/2010-91-CRC-BDEs-Tables.pdf.

[23] Y. Jiang, Y.Y. Sun, M. Chen, Y. Wang, Z. Li, C. Song, K. He, L. Wang, X. Chen, Q.K. Xue, X. Ma, S.B. Zhang, Fermi-level tuning of epitaxial $\mathrm{Sb}_{2} \mathrm{Te}_{3}$ thin films on graphene by regulating intrinsic defects and substrate transfer doping, Phys. Rev. Lett. 108 (2012) 1-5, https://doi.org/10.1103/PhysRevLett.108.066809.

[24] A.J. Green, S. Dey, Y.O. An, B. O'Brien, S. O'Mullane, B. Thiel, A.C. Diebold, Surface oxidation of the topological insulator $\mathrm{Bi}_{2} \mathrm{Se}_{3}$, J. Vac. Sci. Technol.
A Vacuum, Surfaces, Film 34 (2016), 061403, https://doi.org/10.1116/ 1.4964637.

[25] J. Schaumann, M. Loor, D. Ünal, A. Mudring, S. Heimann, U. Hagemann, S. Schulz, F. Maculewicz, G. Schierning, Improving the zT value of thermoelectrics by nanostructuring: tuning the nanoparticle morphology of $\mathrm{Sb}_{2} \mathrm{Te}_{3}$ by using ionic liquids, Dalton Trans. 46 (2017) 656-668, https://doi.org/ 10.1039/c6dt04323b.

[26] G. Hao, X. Qi, Y. Fan, L. Xue, X. Peng, X. Wei, J. Zhong, Spiral growth of topological insulator $\mathrm{Sb}_{2} \mathrm{Te}_{3}$ nanoplates, Appl. Phys. Lett. 102 (2013) 1-5, https://doi.org/10.1063/1.4773587.

[27] J. Zhang, Z. Peng, A. Soni, Y. Zhao, Y. Xiong, B. Peng, J. Wang, M.S. Dresselhaus, Q. Xiong, Raman spectroscopy of few-quintuple layer topological insulator $\mathrm{Bi}_{2} \mathrm{Se}_{3}$ nanoplatelets, Nano Lett. 11 (2011) 2407-2414, https://doi.org/ $10.1021 / \mathrm{nl} 200773 \mathrm{n}$

[28] M.C. Morris, H.F. McMurdie, E.H. Evans, B. Paretzkin, H.S. Parker, N.C. Panagiotopoulos, Nat. Bur. Stand, (U.S.), Monogr, 1981.

[29] M. Baitimirova, J. Andzane, G. Petersons, R. Meija, R. Poplausks, M. Romanova D. Erts, Vapor-solid synthesis and enhanced thermoelectric properties of non-planar bismuth selenide nanoplates on graphene substrate, J. Mater. Sci. 51 (2016) 8224-8232, https://doi.org/10.1007/s10853-016-0097-z.

[30] G. Kunakova, L. Galletti, S. Charpentier, J. Andzane, D. Erts, F. Léonard, C.D. Spataru, T. Bauch, F. Lombardi, Bulk-free topological insulator $\mathrm{Bi}_{2} \mathrm{Se}_{3}$ nanoribbons with magnetotransport signatures of Dirac surface states, Nanoscale 10 (2018) 19595-19602, https://doi.org/10.1039/c8nr05500a.

[31] B. Wiendlocha, Resonant levels, vacancies, and doping in $\mathrm{Bi}_{2} \mathrm{Te}_{3}, \mathrm{Bi}_{2} \mathrm{Te}_{2} \mathrm{Se}$, and $\mathrm{Bi}_{2} \mathrm{Se}_{3}$ tetradymites, J. Electron. Mater. 45 (2016) 3515-3531, https://doi.org 10.1007/s11664-016-4502-9.

[32] Y. Zhang, K. He, C.Z. Chang, C.L. Song, L.L. Wang, X. Chen, J.F. Jia, Z. Fang, X. Dai, W.Y. Shan, S.Q. Shen, Q. Niu, X.L. Qi, S.C. Zhang, X.C. Ma, Q.K. Xue, Crossover of the three-dimensional topological insulator $\mathrm{Bi}_{2} \mathrm{Se}_{3}$ to the two-dimensional limit, Nat. Phys. 6 (2010) 584-588, https://doi.org/10.1038/nphys1689.

[33] L. Zhang, M. Dolev, Q.I. Yang, R.H. Hammond, B. Zhou, A. Palevski, Y. Chen, A. Kapitulnik, Weak localization effects as evidence for bulk quantization in $\mathrm{Bi}_{2} \mathrm{Se}_{3}$ thin films, Phys. Rev. B Condens. Matter 88 (2013) 2-5, https://doi.org/ 10.1103/PhysRevB.88.121103.

[34] M.I. Alomar, D. Sánchez, Thermoelectric effects in graphene with local spinorbit interaction, Phys. Rev. B Condens. Matter 89 (2014), https://doi.org/ 10.1103/PhysRevB.89.115422.

[35] N. Peranio, M. Winkler, Z. Aabdin, J. König, H. Böttner, O. Eibl, Room temperature MBE deposition of $\mathrm{Bi}_{2} \mathrm{Te}_{3}$ and $\mathrm{Sb}_{2} \mathrm{Te}_{3}$ thin films with low charge carrier densities, Phys. Status Solidi Appl. Mater. Sci 209 (2012) 289-293, https://doi.org/10.1002/pssa.201127440.

[36] B. Huang, C. Lawrence, A. Gross, G.S. Hwang, N. Ghafouri, S.W. Lee, H. Kim, C.P. Li, C. Uher, K. Najafi, M. Kaviany, Low-temperature characterization and micropatterning of coevaporated $\mathrm{Bi}_{2} \mathrm{Te}_{3}$ and $\mathrm{Sb}_{2} \mathrm{Te}_{3}$ films, J. Appl. Phys. 104 (2008) 1-9, https://doi.org/10.1063/1.3033381.

[37] J. Navrátil, J. Horák, T. Plecháček, S. Kamba, P. Lošt'ák, J.S. Dyck, W. Chen, C. Uher, Conduction band splitting and transport properties of $\mathrm{Bi}_{2} \mathrm{Se}_{3}$, J. Solid State Chem. 177 (2004) 1704-1712, https://doi.org/10.1016/ j.jssc.2003.12.031.

[38] J.P. Carmo, J. Antunes, M.F. Silva, J.F. Ribeiro, L.M. Goncalves, J.H. Correia, Characterization of thermoelectric generators by measuring the loaddependence behavior, Meas. J. Int. Meas. Confed 44 (2011) 2194-2199, https://doi.org/10.1016/j.measurement.2011.07.015.

[39] G. Bulman, P. Barletta, J. Lewis, N. Baldasaro, M. Manno, A. Bar-Cohen, B. Yang, Superlattice-based thin-film thermoelectric modules with high cooling fluxes, Nat. Commun. 7 (2016) 1-7, https://doi.org/10.1038/ncomms10302.

[40] Y. Min, G. Park, B. Kim, A. Giri, J. Zeng, J.W. Roh, S. Il Kim, K.H. Lee, U. Jeong, Synthesis of multishell nanoplates by consecutive epitaxial growth of $\mathrm{Bi}_{2} \mathrm{Se}_{3}$ and $\mathrm{Bi}_{2} \mathrm{Te}_{3}$ nanoplates and enhanced thermoelectric properties, ACS Nano 9 (2015) 6843-6853, https://doi.org/10.1021/nn507250r. 